\title{
Environmental change and sustainable social development: Social work-social development, Volume II
}

\author{
Sven Hessle (Ed.) \\ Ashgate Publishing, Farnham, England, 2014 \\ ISBN 978-1472416377, pp. 196, Hardback, NZ\$203.09
}

$\mathrm{O}$

nce upon a time in another life,

I worked on a humanitarian aid programme in Angola, West Africa.

I was working in a region originally controlled by the so-called resistance movement in a recently-ended 26-year civil war. The people had long-since been abandoned by any form of central government and the resistance focussed all of its resources on waging war. Thus, apart from roads containing scattered land mines, there was no infrastructure and minimal services. The water supply for a town of perhaps 10,000 people was a small river, with water pumped into a truck and delivered to barrels on street corners, then transferred again into buckets to be carried on the heads of women to their houses.

The inefficiencies of such a system are obvious. But there were also the hidden costs, such as transfer of diseases from river to house, inadequate washing and sanitation facilities, and more. The people very sensibly collected the water upstream, and swam and washed downstream, ensuring some basic water hygiene. But all the villages along river did the same. Thus along with drinking water supply, the river doubled as a sewer and grey water pathway servicing dozens of small villages.

This book attempts to address the alltoo-familiar issues that emerge from dissection of this story. They are issues of community-building, of social awareness, of environmental (mis)management, of economic necessity, of corruption, and of failed governance. They are issues of human rights, of the challenges and opportunities facing the social work profession, and of the desperate need for social workers to proactively attach themselves to humanitarian aid programmes that need to be about much more than food and economic collapse. Chapter three offers an entry into the relevant issues, although they are thematic throughout the book.

The book is one of three volumes emerging from a conference held in Stockholm in July 2012, titled Social Work and Social Development 2012: Action and Impact. The conference was strongly focussed on the UN sustainable development goals (the latest incarnation of which evolved from the UN millennium development goals). The UN-approved global agenda for social work and social development is provided as an appendix of this volume, and is worthy of an in-depth exploration even if no other part of the book is read. Of course, reading the goals will promote a hunger for ideas on how they might be implemented. While light on implementation, this book certainly contains many valuable ideas.

This volume addresses environmental and sustainability issues, and arguably addresses an area in which social work is deficient and needs to be far more proactive. It is unfortunate that psychosocial recovery has not been accorded the same priority as the more obvious immediate needs in a post-disaster situation. Food and medical support and economic recovery tend to dominate that response, albeit for very sensible reasons. But the long-term consequences of post-traumatic stress, of being a child soldier, of losing family, and of broader social disruption, all need to be taken into account and responded to. The conference and this book are a part of that process. 
Chapter two offers an insight into a story from Canada eerily reminiscent of an issue that we usually associate with Australia: discriminatory government policies and the human rights of indigenous children. This is a "watch this space" example, as it is ongoing.

Chapter four offers a series of case studies in disaster management. While attempting to provide a positive view, this chapter essentially documents challenges and opportunities, while providing little on genuine solutions. Some of the authors have so little to offer that one wonders why the case study was written at all. That comment reflects current reality, and is not intended to be critical of the authors themselves, or of their programmes. Perhaps highlighting inadequacies was the reason for including some of those examples.

Chapter five gives two examples of the influence of environmental change on indigenous communities, and of the resilience exhibited in the response. Both are arguably about the effects of climate change and have relevance for any community (indigenous or not) that still relies to some extent on environmental resource gathering for its survival. There are small towns in New Zealand that could learn from these stories.

Chapter six explores the issues underlying labour, children and education (issues that are clearly linked). Chapter seven, on water, documents the increasingly desperate situation for many communities as they battle the twin forces of climate change and global economic development. Chapter eight, on community-based economic development, explores options for resilient responses to modern economic pressures. Chapter nine presents a positive view of globalisation through linking education and the internet.

Chapter ten puts social workers clearly at the centre of a new vision for socially-based environmental sustainability. The chapter discusses how to "green the profession" through supporting local-scale resilience based on sustainable environmental and economic principles. This, most certainly, is not about business-as-usual.

The Global Agenda for Social Work and Social Development for the period 2012-1016 (p. 152) includes the following commitments: i) promoting social and economic equalities; ii) promoting dignity and worth of peoples, iii) working towards environmental sustainability; and iv) strengthening recognition of the importance of human relationships. It is now 2016. You might ask first, what have I done to achieve or support these aspirations, and second, what, if anything, has been achieved in a world where inequality has been inexorably rising (OECD, 2015) and business-as-usual is still strongly defended (by those who benefit from the status quo)? Perhaps the commitments simply need to be reframed on a local scale for genuine implementation, which arguably is the main message of the book.

A great read? Not really. More frustrating, and sometimes a little irritating due to editorial failures. But the book is certainly a useful resource stimulating thought about new roles for an old profession.

\section{References}

OECD (2015). In it Together: Why less inequality benefits all. Paris, France: OECD. doi: http://dx.doi. org/10.1787/9789264235120-en

Reviewed by lan G. McLean Waiariki Institute of Technology 